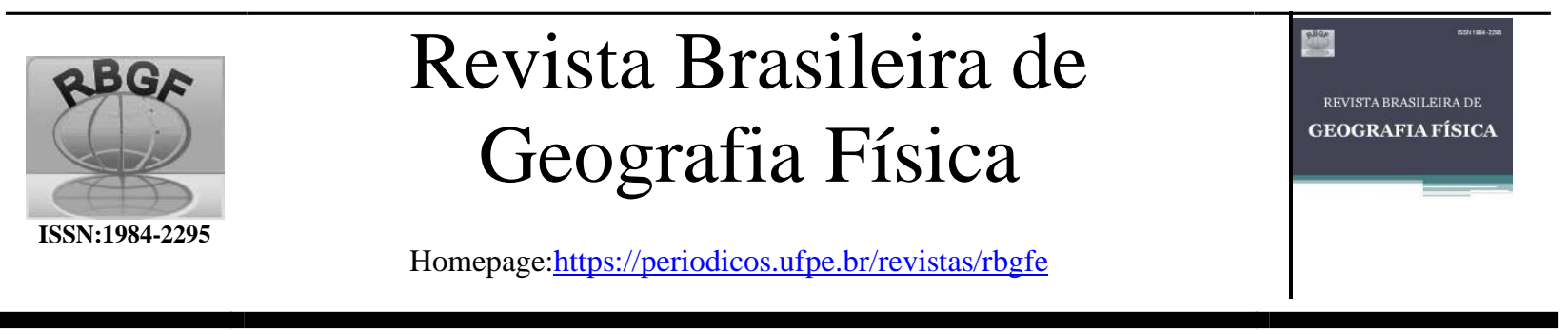

\title{
Morfologia e Sedimentação em Praias Oceânicas da Amazônia Oriental durante a Variação Anual de Chuvas
}

\author{
Leilanhe Almeida Ranieri' ${ }^{1}$, Maâmar El-Robrini²
}

\begin{abstract}
${ }^{1}$ Professora Efetiva da Faculdade de Oceanografia e Programa de Pós-graduação em Oceanografia, Universidade Federal do Pará, Belém, PA, Brasil. E-mail: laranieri@ufpa.br

${ }^{2}$ Professor Titular da Faculdade de Oceanografia, Programa de Pós-Graduação em Engenharia Naval e Programa de Pós-graduação em Oceanografia, Universidade Federal do Pará, Belém, PA, Brasil. E-mail: robrini@ufpa.br
\end{abstract}

Artigo recebido em 06/05/2020 e aceito em 09/07/2020

\section{R E S U M O}

Este artigo buscou analisar os efeitos dinâmicos da sazonalidade climática sobre a morfologia e sedimentação de praias oceânicas da Amazônia durante as estações chuvosa e menos chuvosa. A importância deste estudo foi demonstrar um comportamento deposicional de sedimentos nestas praias de uma estação climática à outra. A metodologia consistiu em perfilagem topográfica nas praias dos setores: oeste (Corvina e Maçarico), central (Farol Velho) e leste (Atalaia) de Salinópolis (PA), amostragem de sedimentos, análise granulométrica com aplicação de parâmetros estatísticos e medições de altura e período de ondas. O diâmetro médio dos sedimentos consistiu predominantemente de areia fina (2,6 a 2,8 phi), muito bem a bem selecionada $(0,2$ a 0,5$)$. A assimetria variou, principalmente, entre positiva $(0,10$ a 0,30$)$ e aproximadamente simétrica $(-0,10$ a 0,10$)$. O grau de curtose entre muito platicúrtica $(<0,67)$ a muito leptocúrtica $(1,50$ a 3,00 ). As alturas de ondas foram mais elevadas no setor leste (máximo de $1,05 \mathrm{~m}$ ) e períodos de ondas foram mais curtos $(<4,5 \mathrm{~s})$ no setor oeste. As praias apresentaram declives suaves $\left(<1,5^{\circ}\right)$ e grandes variações na largura entre as estações do ano $(9,6$ a 88,4 m). Predominou o estado morfodinâmico dissipativo $(\Omega>5,5)$, mas com ocorrência do estado de banco e calha longitudinais $(4,7<\Omega<5,5)$ no setor oeste. Foi observada acreção sedimentar da estação chuvosa a menos chuvosa em todas as praias. $\mathrm{O}$ transporte transversal de sedimentos foi elevado, especialmente no sentido onshore (máximo: 11 x10${ }^{3} \mathrm{~kg} / \mathrm{s} / \mathrm{m}$, setor leste). No setor central foi baixo (mínimo: $0,72 \times 10^{-3} \mathrm{~kg} / \mathrm{s} / \mathrm{m}$ ), favorecendo tendências erosivas neste local. Palavras-chave: Praia, Morfodinâmica, Granulometria, Amazônia.

\section{Morphology and Sedimentation in Ocean Beaches in the Eastern Amazon during the Annual Rain Variation}

\begin{abstract}
A B S T R A C T
This paper aimed to analyze the dynamic effects of climatic seasonality on the morphology and sedimentation of oceanic beaches in the Amazon during the rainy and less rainy seasons. The importance of this study was to demonstrate a depositional behavior of sediments on these beaches from one climatic season to another. The methodology consisted of topographic profiling on the beaches of the sectors: west (Corvina and Maçarico), central (Farol Velho) and east (Atalaia) of Salinópolis (PA), sediment sampling, grain-size analysis with application of statistical parameters and measurements of height and wave period. The mean diameter of the sediments consisted predominantly of fine sand (2.6 to 2.8 phi), well sorted and very well sorted ( 0.2 to 0.5$)$. The asymmetry varied, mainly, between positive $(0.10$ to 0.30$)$ and nearly symmetrical $(-0.10$ to 0.10$)$. The degree of kurtosis between very platykurtic $(<0.67)$ to very leptokurtic $(1.50$ to 3.00$)$. The wave heights were higher on the eastern sector (maximum $1.05 \mathrm{~m}$ ) and wave periods were shorter $(<4.5 \mathrm{~s})$ on the western sector. The beaches presented smooth slopes $\left(<1.5^{\circ}\right)$ and great variations in width between the seasons $(9.6$ to $88.4 \mathrm{~m})$. The dissipative morphodynamic state $(\Omega>5.5)$ predominated, but with the occurrence of the longshore bar and trough $(4.7<\Omega<5.5)$ in the western sector. Sedimentary accretion from the rainy to less rainy season was observed on all beaches. Cross-shore sediment transport was high, especially in the onshore (maximum: $11 \times 10^{-3} \mathrm{~kg} \cdot \mathrm{s}^{-1} \cdot \mathrm{m}^{-1}$, east sector). In the central sector it was low (minimum: $0.72 \times 10^{-3} \mathrm{~kg} \cdot \mathrm{s}^{-1} \cdot \mathrm{m}^{-1}$ ), favoring erosive trends in this location.
\end{abstract}

Keywords: Beach, Morphodynamic, Grain-Size, Amazon.

\section{Introdução}

A morfodinâmica de praia está relacionada a interações complexas que envolvem descarga de

Ranieri, L. A., El-Robrini, M. 
água e sedimentos de estuários, orientação de linha de costa, correntes costeiras, ondas, correntes das marés (Brand et al., 2020), que são as principais condicionantes da topografia e transporte de sedimentos em praias de macromarés (amplitude $>4 \mathrm{~m}$ ).

A dinâmica complexa e variável, que caracteriza as contínuas alterações morfológicas e sedimentares em praiais, ocorre devido aos efeitos desta ampla quantidade de processos hidromorfodinâmicos. Os ventos, as ondas, as correntes e as marés, interagem em diferentes escalas espaciais e temporais (Alvarez-Ellacuria et al., 2010).

As evidências destas alterações são constatadas por vários métodos e equipamentos destinados à análise da morfosedimentação em praias. Eles se baseiam, por exemplo, em dados adquiridos indiretamente, como por técnica de sensoriamento remoto, para verificar mudanças morfológicas multitemporais de pequena e grande escala (Ranieri e El-Robrini, 2015). Ou por meio de dados adquiridos in situ com auxílio de sensores ópticos ou acústicos, para verificar a hidrodinâmica; e a realização de perfis de praia (amostragens de sedimentos e medições da topografia) para obtenção das modificações do volume sedimentar, de modo bidimensional ou tridimensional.

Os estudos abordando a distribuição sedimentar em praias e, os fatores hidrodinâmicos condicionantes, permitem traçar um fluxo da carga sedimentar costeira, que tem implicações na sua forma. Pois a abordagem morfodinâmica considera as interações entre a hidrodinâmica e a morfologia, seus feedbacks positivo e negativo e o acoplamento resultante que mantém alterável a sua configuração ao longo da zona costeira (Short, 2012).

As praias arenosas podem variar significativamente de seu estado inicial, dependendo da sazonalidade, vegetação, mudança das condições de ondas e marés, alterando a largura e extensão (Erickson et al., 2017), sendo susceptíveis à erosão, ao transporte e, por fim, à distribuição granulométrica.

A análise da distribuição do tamanho de grão tem sido amplamente utilizada por sedimentologistas para classificar ambientes sedimentares e elucidar a dinâmica de transporte (Ayodele e Madukwe, 2019). A distribuição da frequência do tamanho dos grãos e os fatores texturais podem refletir o modo de transporte e a história deposicional de uma área.

A trajetória do transporte sedimentar numa praia é, por sua vez, controlada pelas forçantes hidrodinâmicas (ondas, marés, correntes, descarga fluvial) e eólicas (ventos) que atuam simultaneamente.

Em Salinópolis, litoral amazônico, estas forçantes atuam em níveis de energia moderado a alto, pois existem praias oceânicas expostas e semiexpostas às ondas, aos constantes ventos alísios de $\mathrm{NE}$, e sujeitas ao regime de macromarés (Braga et al., 2019). Além disso, praias de meso-macromarés da Amazônia Oriental estão sob a influência do clima equatorial, das condições oceanográficas da plataforma continental amazônica e dos padrões físicos e sedimentares de grandes estuários que deságuam nesta costa.

Poucos estudos têm sido publicados sobre as praias de meso-macromarés amazônicas, que apresentam peculiaridades importantes, como a elevada vazão e aporte sedimentar dos rios/estuários em decorrência dos altos índices de precipitação, a elevada intensidade das correntes de marés e a presença de moderada a alta energia dos ventos e, consequentemente, das ondas, que são moduladas pela presença de bancos/barras arenosas (Pereira et al., 2013; Oliveira et al., 2014; Nascimento e Pereira, 2016; Ranieri e El-Robrini, 2016; Braga et al., 2019).

Um exemplo disto são as praias de Salinópolis, inseridas numa costa bastante diversificada quanto às características naturais, com importantes estuários e canal de maré que contribuem como fontes de sedimentos, intensificação da hidrodinâmica e formação de barras arenosas offshore, onde níveis de modulação atuam de forma sazonal. Nestas praias, falésias, dunas, manguezais e estruturas rígidas de proteção costeira limitam a linha de costa, permitindo também trocas sedimentares distintas.

Acredita-se que a distribuição granulométrica nas praias e, a consequente morfodinâmica, resulta não somente da interação dos processos físicos com estas diferentes feições fisiográficas presentes na linha de costa, mas também está relacionada com as alterações climáticas sazonais que influenciam no perfil de equilíbrio das praias, com tendências mais deposicionais da estação chuvosa a menos chuvosa.

Este artigo objetiva mostrar os efeitos da sazonalidade climática sobre a Costa Atlântica amazônica, tendo como estudo de caso as praias de Salinópolis, evidenciando suas alterações morfológicas (topografia, bancos/calhas arenosos), sedimentares (diâmetro médio, dispersão dos 
grãos) e hidrodinâmicas (transporte transversal de sedimentos).

\section{Material e Métodos}

Área de Estudo - A área de estudo está localizada no município de Salinópolis ( $0^{\circ} 37^{\prime} 53$ 'S e 47²0’46”W), Nordeste do Pará, Brasil, e foi dividida em três setores distintos: Oeste (praias da Corvina e Maçarico), Central (praia do Farol Velho) e Leste (praia do Atalaia) (Figura 1).

As praias de Salinópolis são limitadas na linha de costa por: manguezais, dunas costeiras, falésias, estruturas urbanas e de contenção de erosão (Ranieri e El-Robrini, 2015). Além disso, interceptam a costa: canais de marés e estuários.
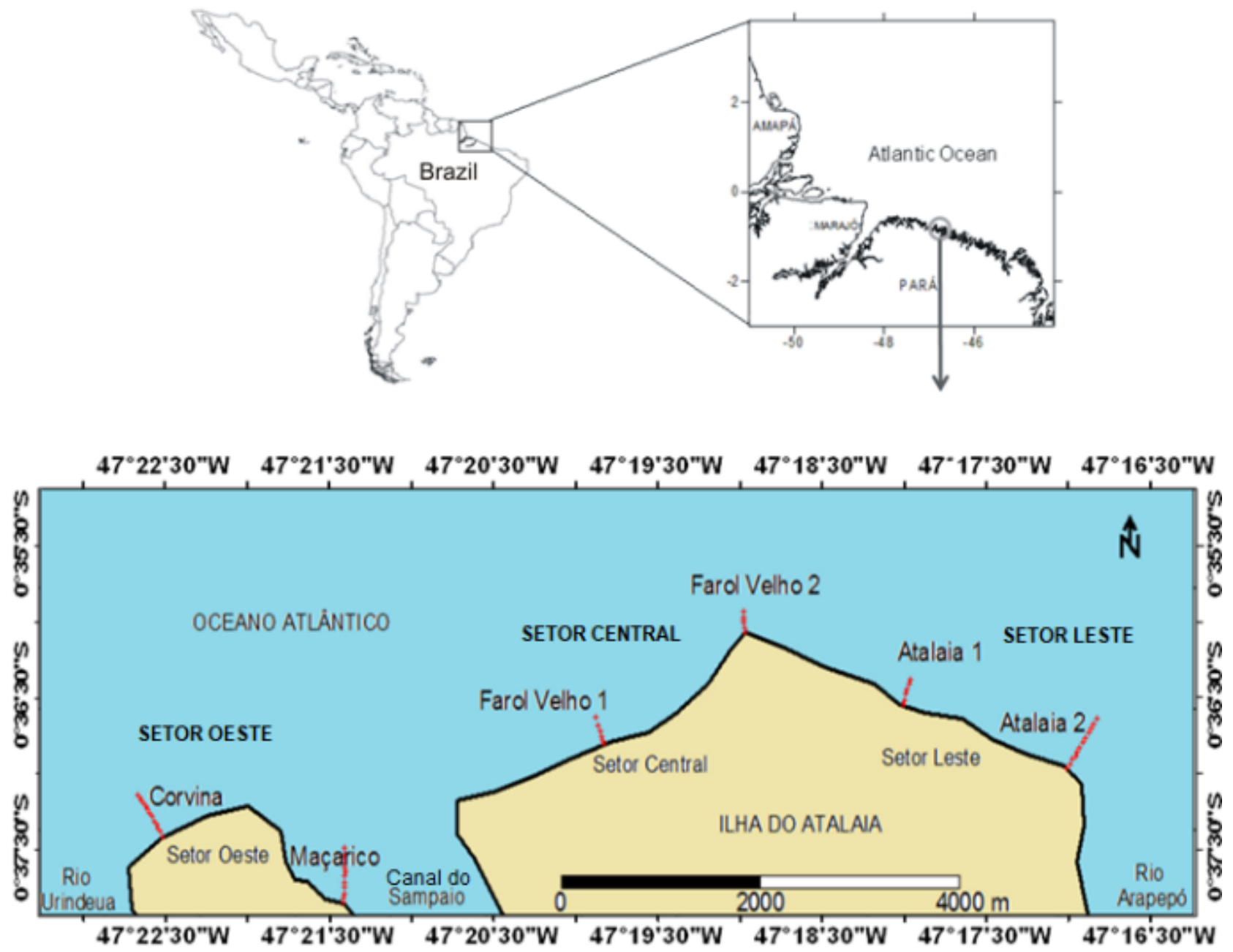

Figura 1. Mapa de localização das praias oceânicas de Salinópolis, setores estudados e perfis realizados.

A geologia do município de Salinópolis é constituída principalmente pelos sedimentos da Formação Barreiras e Pós-Barreiras, ocupando a maior distribuição espacial de seu território; por rochas carbonáticas da Formação Pirabas; e por sedimentos recentes do Quaternário (Braga et al., 2019).

A presença de falésias deixa evidente os sedimentos da Formação Barreiras e Pós-Barreiras na foz do rio Sampaio (praia do Maçarico) e reentrâncias das baías que recortam o município. Já os afloramentos da Formação Pirabas são encontrados bem expostos na praia do Farol Velho, e de maneira menos exposta nas praias de Atalaia e do Maçarico.

Sobre os sedimentos Pós-Barreiras ocorrem depósitos recentes do Quaternário que formam feições geomorfológicas características do NE do Pará em forma de extensos depósitos de lama em planície de maré, além de planícies arenosas, cheniers, dunas, deltas de marés, praiasbarreiras e leques de lavagens (El-Robrini et al., 2018). 
O clima na área de estudo é do tipo Am (Tropical Úmido) que é caracterizado por ser quente e úmido (Clima Equatorial Amazônico). A média anual da umidade relativa do ar varia entre $80 \%$ a $90 \%$ e a temperatura média é de $27{ }^{\circ} \mathrm{C}$ (CPTEC, 2014).

O ciclo sazonal das chuvas na costa amazônica é marcado fortemente pelo movimento migratório latitudinal da ZCIT, definido como o máximo em precipitação tropical ou como um cinturão tropical de nuvens convectivas, e sua posição média varia sazonalmente de $9^{\circ} \mathrm{N}$ a $2^{\circ} \mathrm{N}$ no Oceano Atlântico Equatorial (Utida et al., 2019).

A estação menos chuvosa ocorre de junho a novembro, quando a ZCIT se desloca para o Hemisfério Norte e o nível de precipitação é menor. Já a estação chuvosa ocorre de dezembro a maio, quando a ZCIT está mais ao Hemisfério Sul e as chuvas são mais intensas. No município de Salinópolis, a média anual da precipitação é de $2.800 \mathrm{~mm}$ (ANA, 2013).

O regime de ventos dominante é representado pelos alísios de NE que atuam continuamente durante o ano todo. Estes ventos são responsáveis pelo transporte de sedimentos da plataforma continental interna em direção à costa (Geyer et al., 1996).

A partir de dados da estação SYNOP (Estação de Superfície Terrestre) do Instituto Nacional de Pesquisas Espaciais (INPE) foi possível constatar que a velocidade dos ventos em 2013 no município de Salinópolis foi em média de $4,0 \mathrm{~m} / \mathrm{s}$ (CPTEC, 2014), sendo a variação da direção de $10^{\circ}$ a $190^{\circ}$, mas predominantemente com a incidência dos ventos alísios de NE $\left(10-90^{\circ}\right)$.

O município sofre influência de ondas originadas pelos ventos alísios que atuam através da plataforma continental rumo a oeste, gerando frentes de ondas incidentes, que associados à morfologia de fundo, dão origem às correntes de deriva litorânea para noroeste (Geyer et al. 1996). Segundo o modelo WWATCH (CPTEC, 2013), as alturas de onda em Salinópolis variam entre 0,5 a $1,5 \mathrm{~m}$.

Macromarés (amplitudes $>4 \mathrm{~m}$ ) semidiurnas dominam na área de estudo, onde as correntes de marés são as principais correntes costeiras que atuam no NE do Pará. Nas praias de Salinópolis, as correntes atingem cerca de $0,5 \mathrm{~m} / \mathrm{s}$ (Ranieri e El-Robrini, 2016).

Amostragem - Foram realizadas coletas de dados durante um ciclo sazonal $(26,27 \mathrm{e}$ 28/04/2013 - estação chuvosa - e 04, 05 e
06/10/2013 - estação menos chuvosa) visando analisar a evolução na morfologia e sedimentação das praias de Salinópolis, durante as duas estações climáticas amazônicas.

Os trabalhos desempenhados correspondem ao método de perfil de praia: levantamento topográfico e amostragem de sedimentos superficiais, que foram realizados em 6 pontos de estudo, distantes cerca 1,5 km (Figura 1). Além de coleta de dados hidrodinâmicos e sedimentos transportados transversalmente.

Em cada setor da costa, durante as marés vazante e enchente, coletou-se estes sedimentos com o uso de uma armadilha (instrumento composto por uma rede de captura de $63 \mu \mathrm{m}$ e 10 $\mathrm{cm} \mathrm{H} \times 20 \mathrm{~cm} \mathrm{~L} \times 60 \mathrm{~cm} \mathrm{P}$; Figura 1). Esta armadilha operou por 5 minutos no final da zona de espraiamento, ora no sentido contrário ao mar, ora no sentido contrário ao continente. O objetivo foi comparar o volume de sedimentos trazidos e removidos da praia durante o fluxo (swash) e refluxo (backwash) das ondas.

Parâmetros de onda foram medidos em cada setor (Figura 1), antes da perfilagem topográfica, com o intuito de se obter os dados de altura e período de ondas, requeridos para posterior cálculo de estado morfodinâmico de praia.

A altura significativa $(\mathrm{Hb})$ foi medida através da filmagem de 11 cristas de ondas consecutivas numa torre de metal, com dimensões conhecidas, colocada na zona de arrebentação, que serviu para calcular $\mathrm{Hb}$. O tempo da passagem dessas ondas foi dividido pelo número cristas registrado e assim obtido o período delas (T) (Muehe, 2002).

Para a obtenção de dados da morfologia das praias foram realizados os levantamentos topográficos com auxílio de uma Estação Total, marca Topcon GTS 212, durante a maré baixa de sizígia. Os levantamentos tiveram início a partir da linha de costa em pontos fixos (barracas, casas, estruturas de concreto) até a linha de maré baixa de sizígia e, forneceram a representação gráfica das feições sedimentares observadas, além de mostrarem a tendência erosiva ou deposicional nos 3 setores da costa durante a mudança das estações do ano. Foram definidos dois perfis por setor (Figura 1).

Para os dados sedimentológicos foram recolhidas amostras de sedimentos superficiais (5 $\mathrm{cm}$ ), nos mesmos locais de medições de topografia (Figura 1): zonas de supramaré, intermaré superior, média, inferior e inframaré. Zonação adequada 
para as praias de meso-macromarés da costa amazônica (Souza Filho et al., 2003).

Análise dos dados - No laboratório de Sedimentologia, as amostras de sedimentos foram submetidas a lavagem, para remoção de sais, e separação de frações granulométricas por meio do método de peneiramento a seco. Apenas silte e argila foram separados por peneiramento à úmido e separador em centrífuga.

Em seguida, as amostras foram secadas em estufa a $60{ }^{\circ} \mathrm{C}$ e, após esta etapa, foi feito o quarteamento das amostras, a seleção de alíquotas de $100 \mathrm{~g}$ para cada amostra quarteada e peneiramento das mesmas por cerca de $10 \mathrm{~min}$, utilizando-se peneiras com os seguintes intervalos em mm: 0,71 - 0,50-0,35-0,25-0,18-0,125$0,09-0,063-<0,063$. Por fim, as diferentes frações granulométricas foram pesadas em balança semi-analítica.

Através do software SysGran 3.0 foram determinados os parâmetros estatísticos granulométricos (média, seleção, assimetria e curtose) de Folk e Ward (1957) e a classificação de Wentworth (1922) para definição dos sedimentos arenosos. Foram ainda utilizados os aplicativos do pacote Golden Software: Surfer 8, para geração de mapas da distribuição granulométrica e, Grapher 5, para os gráficos de perfil praial.

Foram calculados no programa Microsoft Office Excel, parâmetros morfométricos sugeridos por Short e Hesp (1982): declividade da face praial $(\beta)$, volume sedimentar $\left(\mathrm{m}^{3} / \mathrm{m}\right)$, largura da praia $(\mathrm{Yb})$ e desvio padrão da largura da praia $(\sigma \mathrm{Yb}) . \mathrm{O}$ primeiro parâmetro, expresso em graus, foi obtido através da fórmula:

\section{$\operatorname{Tan} \beta=$ oposto/adjacente (1).}

Onde o dado oposto corresponde à altura e o dado adjacente corresponde à distância entre o máximo e o mínimo valor registrado do perfil topográfico.

Tais parâmetros morfométricos foram calculados com o intuito de relacioná-los aos estados morfodinâmicos de Wright e Short (1984), e Masselink e Short (1993), e fornecem detalhamento para a análise da sazonalidade das alterações morfodinâmicas.

Wright \& Short (1984), propuseram a classificação de praias através do parâmetro empírico adimensional ômega $(\Omega)$ :

$$
\Omega=\mathrm{Hb} / \mathrm{Ws} * \mathrm{~T}(2)
$$

Onde $\mathrm{Hb}$ é a altura significativa da onda na arrebentação, Ws é a velocidade de decantação de partículas sedimentares e T é o período de ondas.

A velocidade de decantação das partículas sedimentares (Ws), requerida para o cálculo de estado morfodinâmico, foi obtida a partir da granulometria média, como estabelecido por Dean (1973).

Masselink e Short (1993) também propuseram a classificação de praias, quanto ao estado morfodinâmico, incluindo o parâmetro máré:

$$
\mathrm{RTR}=\mathrm{MSR} / \mathrm{Hb}^{*} \mathrm{~T}(3)
$$

A variação da maré (MSR) foi obtida através da Tábua de Marés, para os dias de amostragem, disponível gratuitamente pelo Centro de Hidrografia da Marinha do Brasil (DHN, 2013).

\section{Resultados e Discussão}

Morfologia X Sedimentação - Nos perfis de praia realizados (Figuras 2, 3, 4) verificou-se uma tendência no padrão longitudinal dos mesmos: a diminuição da granulometria dos sedimentos (> phi) nos últimos metros da face praial, correspondente à zona de inframaré (último ponto de cada perfil praial), evidenciando a distribuição sedimentar comum de praias e outros ambientes de sedimentação em decorrência da relação entre o tamanho do grão e a energia do meio.

Desta forma, os grãos mais grosseiros ou menos finos são os primeiros a decantar na face praial durante o transporte transversal e espraiamento das ondas (Wright e Short, 1984; Short, 1999), devido serem mais pesados, aumentando a permeabilidade do solo e a inclinação da praia.

Isto é resultado de um equilíbrio dinâmico entre o fluxo de água até a face da praia e o retorno do fluxo da água na face (Susanta, 2018).

Os grãos mais finos são direcionados à parte baixa ou submersa da praia, além de serem agrupados à massa de sedimentos transportados longitudinalmente.

A presença de barras arenosas e calhas longitudinais na zona de intermaré implicou também numa relação específica entre a morfologia e sedimentologia das praias estudadas: aumento do diâmetro médio dos sedimentos nas calhas, pois grãos maiores $(<$ phi) tendem a decantar no meio do canal e os mais finos (>phi), nas bordas do canal. À medida que aumenta a elevação do terreno, fora da área de calha, 
normalmente verifica-se a deposição de grãos mais finos (Figuras 2, 3 e 4).

$\mathrm{Na}$ praia do Maçarico, em abril/2013 (Figura 2c), um pico decrescente no valor da granulometria da zona de inframaré foi devido neste local ter ocorrido afloramento rochoso e, consequentemente, grãos maiores fragmentados. Assim como ocorreu na zona de intermaré superior do Farol Velho 2, em abril/2013 (Figura 3c). No setor central, estes afloramentos estiveram presentes, inclusive desde a linha de maré alta, evidenciando a alta erosão no local.

Não foram observadas mudanças significativas de migração de bancos-calhas longitudinais nas praias, apenas variações em número e na ausência/ocorrência entre os meses estudados. Pois ambientes de macromarés semidiurnas induzem um curto período de exposição dos bancos para os processos de ondas e correntes, podendo assim limitar seu retrabalhamento (Ranieri e El-Robrini, 2012).

Robin et al. (2009), ao estudarem um banco de intermaré em Regnéville, Normandy (França), associaram as baixas taxas de migração do banco também aos efeitos das macromarés.
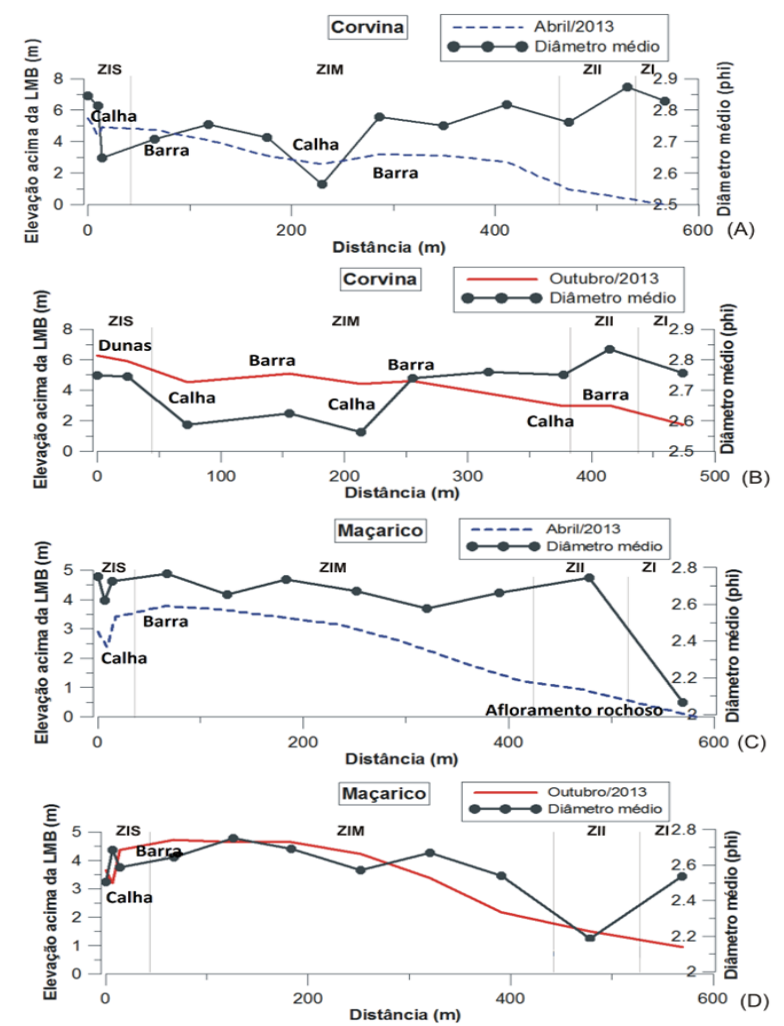

Figura 2. Relação morfologia x granulometria no setor oeste: Corvina (A) (B); Maçarico (C) (D). ZIS: Zona de Intermaré Superior; ZIM: Zona de Intermaré Média; ZIS: Zona de Intermaré Inferior; ZI: Zona de Inframaré. LMB:Linha de Baixa-Mar.
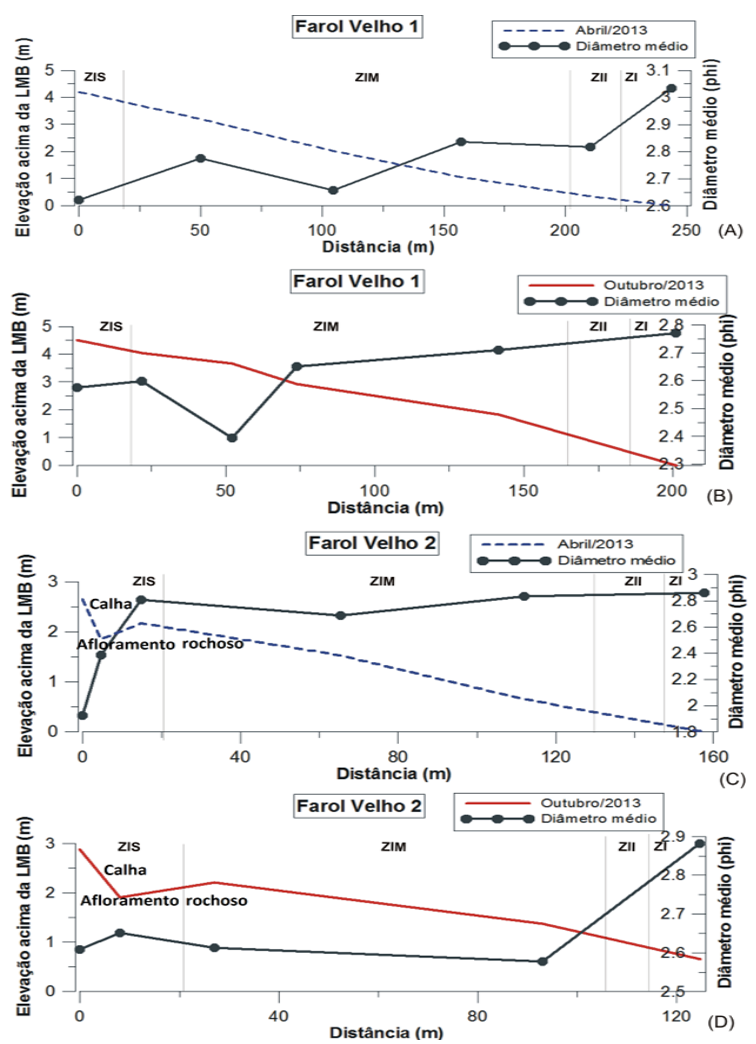

Figura 3. Relação morfologia $x$ granulometria no setor central: Farol Velho 1 (A)(B) e 2 (C)(D). ZIS: Zona de Intermaré Superior; ZIM: Zona de Intermaré Média; ZIS: Zona de Intermaré Inferior; ZI: Zona de Inframaré. LMB:Linha de Baixa-Mar.

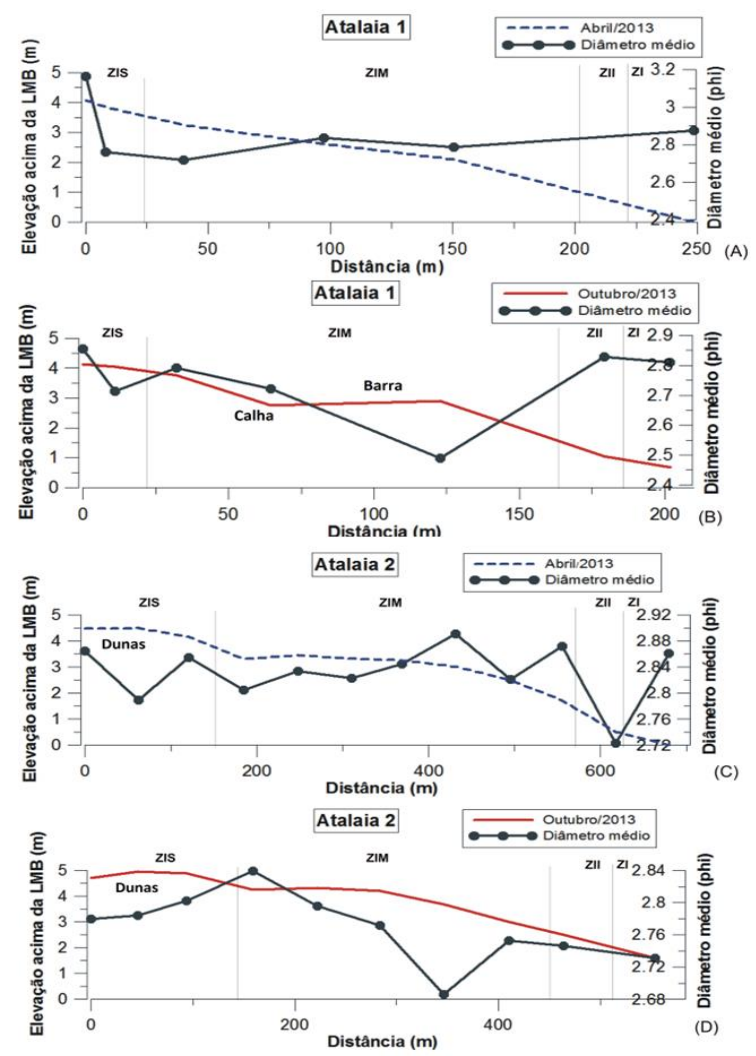

Figura 4. Relação morfologia $x$ granulometria no setor leste: Atalaia 1 (A) (B) e 2 (C) (D). ZIS: Zona 
de Intermaré Superior; ZIM: Zona de Intermaré Média; ZIS: Zona de Intermaré Inferior; ZI: Zona de Inframaré. LMB:Linha de Baixa-Mar.

Como o deslocamento da água em direção à linha de costa é maior em praias de macromarés, ocorre também maior mudança na posição da zona de arrebentação. No caso de marés semidurnas, este deslocamento é ainda mais rápido, inibindo um retrabalhamento mais eficaz em feições específicas no perfil praial, como os bancos-calhas longitudinais.

Outros estudos realizados nas praias do norte da França mostraram características semelhantes às praias de macromaré amazônicas com morfologia de banco-calha quase permanente, seja na zona de intermaré ou inframaré, mesmo sob condições de ondas de tempestade (Sipka e Anthony, 1999; Voulgaris et al., 1998; Levoy et al., 2000; Masselink e Anthony, 2001; Anthony et al., 2004; Reichmüth e Anthony, 2008; Cartier e Héquette, 2015).

Calhas longitudinais estiveram presentes desde a linha de maré alta no setor oeste (Figura 2), relacionadas com um pequeno canal de maré que atravessa transversalmente as praias deste setor, com ramificações paralelas à linha de costa na zona de intermaré superior (Figuras 5a e 5b), zona onde cessa o efeito da energia de ondas, mas que ainda é inundada pelas subidas das marés.

Nos perfis topográficos realizados nas praias da Corvina apareceram três sistemas de banco-calha em outubro/2013 (Figura 2b), anteriormente (abril/2013) houve apenas dois (Figura 2a). A ocorrência desses sistemas no setor oeste deve-se ao grande número de barras de maré vazante presentes na foz do estuário de Urindeua, a oeste, e no canal de maré do Sampaio, a leste. Estas barras arenosas migram gradativamente à praia, em função da deriva costeira.

Durante o verão (estação menos chuvosa amazônica), há menor quantidade de energia turbulenta, sendo que as areias removidas, na estação anterior, para trás da zona de arrebentação de ondas, tendem a migrar novamente em direção à praia (Masselink e Short, 1993). Grande parte destes sedimentos estão configurados em bancos/barras arenosas.

Darsan (2013) também associou a migração em direção onshore de bancos-calhas longitudinais em praias do Mar do Caribe com a acreção sedimentar ocorrente durante o verão.

No perfil Farol Velho 1 não foi verificado feição de banco-calha longitudinal (Figuras 3a e 3b). No perfil Farol Velho 2 ocorreu uma depressão (poças d'água) semelhantes à calha na linha de costa (Figura 3a), mas devido aos afloramentos rochosos que ocorrem no setor central e parte da praia do Atalaia (Figuras 5c e 5d). Estes afloramentos fazem com que os sedimentos fiquem retidos na parte superior desta formação rochosa e, na porção inferior dela, desenvolve-se a depressão pela ação das ondas. Quando o alcance da maré é maior sobre a praia (estação mais chuvosa), o nível de turbulência é mais elevado sobre esta feição do perfil Farol Velho 2.

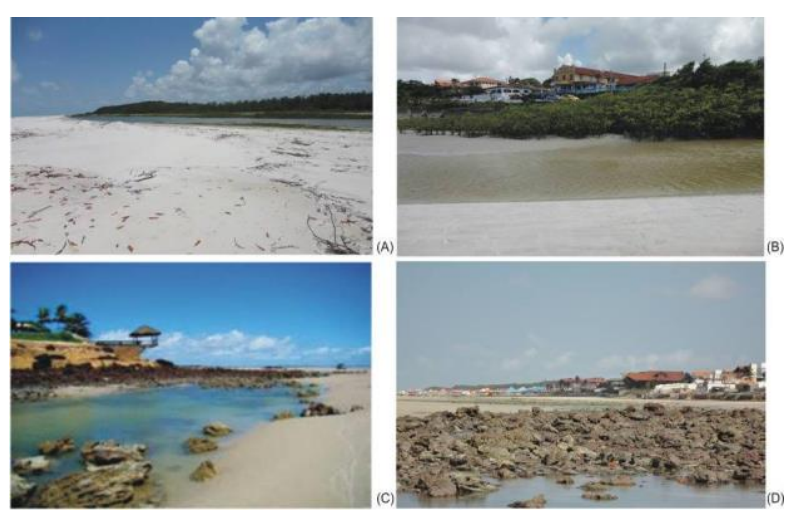

Figura 5. Ramificações, paralelas à linha de costa, do canal de maré que atravessa o setor oeste: praia da Corvina (A) e praia do Maçarico (B). Afloramentos de rochas carbonáticas (Formação Pirabas) na linha de maré alta do Farol Velho 2, propiciando o desenvolvimento de uma calha longitudinal (C). Afloramentos expostos na zona de intermaré a oeste da praia do Atalaia (D).

Observa-se, nos perfis do setor central, assim como nos outros perfis de praias realizados na área de estudo, maior deposição de sedimentos na face praial durante a estação menos chuvosa. Pois houve topografia mais elevada e, consequentemente, maior volume sedimentar nesta estação climática (Figuras 2, 3 e 4). Kouekam et al. (2020) também registraram maior acúmulo sedimentar na praia de Idenau, costa oeste de Camarões, onde precipitações anuais também são acentuadas. Contudo, este acúmulo sedimentar foi desde meados da estação mais chuvosa.

As praias costumam perder areia em direção offshore durante a estação chuvosa, devido os estuários e canais de marés apresentarem maior vazão fluvial e de haver maior fluxo turbulento pelas ondas e correntes de maré, resultado das condições meteorológicas intensas. Esta característica segue o modelo morfológico de Short (2003) para praias de meso-macromarés.

Brand et al. (2019) ao estudarem uma praia de macromaré da Bélgica constataram evidências deste modelo. Pelo menos uma parte do sedimento 
que foi mobilizado da zona de intermaré durante condições mais energéticas foi depositado logo abaixo da linha de baixa-mar. Durante condições mais calmas, esse sedimento foi transportado de volta para a zona de intermaré.

No inverno (estação chuvosa amazônica), a perda de areia para o transporte offshore, permite a formação das barras arenosas a centenas de metros da costa (Ranieri e El-Robrini, 2012). E, como dito anteriormente, no verão (estação menos chuvosa), elas tendem a migrar em direção à praia.

Holanda et al. (2020) também identificaram perfis de erosão mais acentuados no inverno e outono na praia da Paiva (PE), contudo devido ao clima de onda e retirada de sedimentos da berma.

Esta feição sedimentar não é comum nas praias oceânicas da costa amazônica. Sendo evidentes as dunas frontais escarpadas e os bancos e calhas nas praias.

No perfil Atalaia 1, em outubro, ocorreu um sistema de banco-calha longitudinal na zona de intermaré média (Figura 4b). A ocorrência desse sistema pode ser atribuída a esta migração de barras de maré vazante presentes na foz do estuário de Arapepó, em direção à linha de costa. Tal estuário limita a Ilha de Atalaia na sua margem oriental.

No Atalaia 2 houve uma depressão semelhante a calha longitudinal na zona de intermaré média em função da transição da face praial mais plana para o extenso campo de dunas frontais, que exibe forma mais irregular. Este campo de dunas teve menor proporção na estação chuvosa (Figura 6a) e maior proporção na estação menos chuvosa (Figura 6b), quando os ventos foram os mais intensos do ano (média de $5,3 \mathrm{~m} / \mathrm{s}$ em outubro/2013), segundo CPTEC (2014). As dunas foram observadas também nas zonas de supramaré do Atalaia 1 (Figuras 6c) e Corvina (Figuras 6d).

As forçantes marés e ventos são responsáveis por importantes mudanças morfológicas de praia, como a erosão das dunas anteriormente depositadas, durante os períodos de marés mais altas na estação chuvosa amazônica. Além disso, a maré pode desempenhar um papel importante no transporte destes sedimentos (Brand et al., 2020).

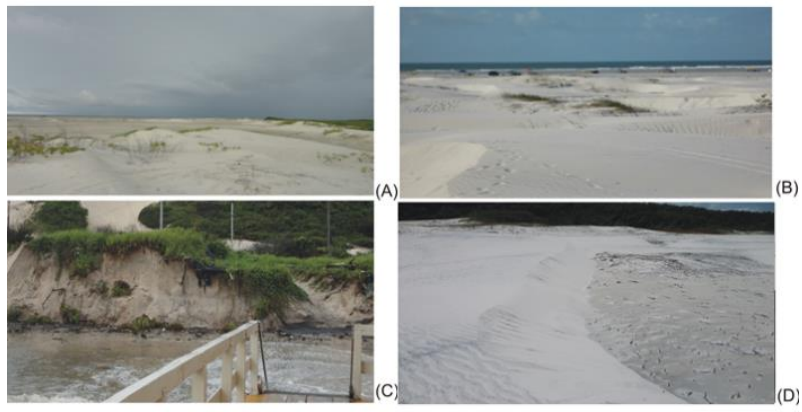

Figura 6. Campo de dunas frontais na zona de intermaré superior do Atalaia $2 \mathrm{em}$ abril (A) e outubro de 2013 (B). Dunas escarpadas no Atalaia $1 \mathrm{em}$ abril (C). Campo de dunas frontais dispostos nas zonas de supramaré e intermaré superior da praia da Corvina (D).

Estado Morfodinâmico - As praias de Salinópolis enquadram-se, segundo a classificação de Masselink \& Short (1993), como modificadas por maré $(3<\mathrm{RTR}<15)$ (Figuras 7 e 8$)$, sendo ultradissipativas $(7<\mathrm{RTR}<15)$ no setor oeste e intermediária $(3<$ RTR $<7)$ no setor leste, durante as duas estações do ano. Na estação chuvosa, esta última classificação também foi verificada no setor central, e durante a estação menos chuvosa, a praia foi classificada como ultradissipativa.

De acordo com a classificação de Wright e Short (1984), as praias dissipativas, com valor de $\Omega$ superior a 5,5 ocorreram na Corvina (setor oeste), apenas durante a estação chuvosa, e nos setores central e leste (Figuras 7 e 8). Praias intermediárias, com valor de $\Omega$ entre 4,7 e 5,5 (Figuras 7 e 8), ocorreram no setor oeste, são praias com barras e calhas longitudinais (longshore bar and trough) bem desenvolvidas na zona de inframaré e offshore. 


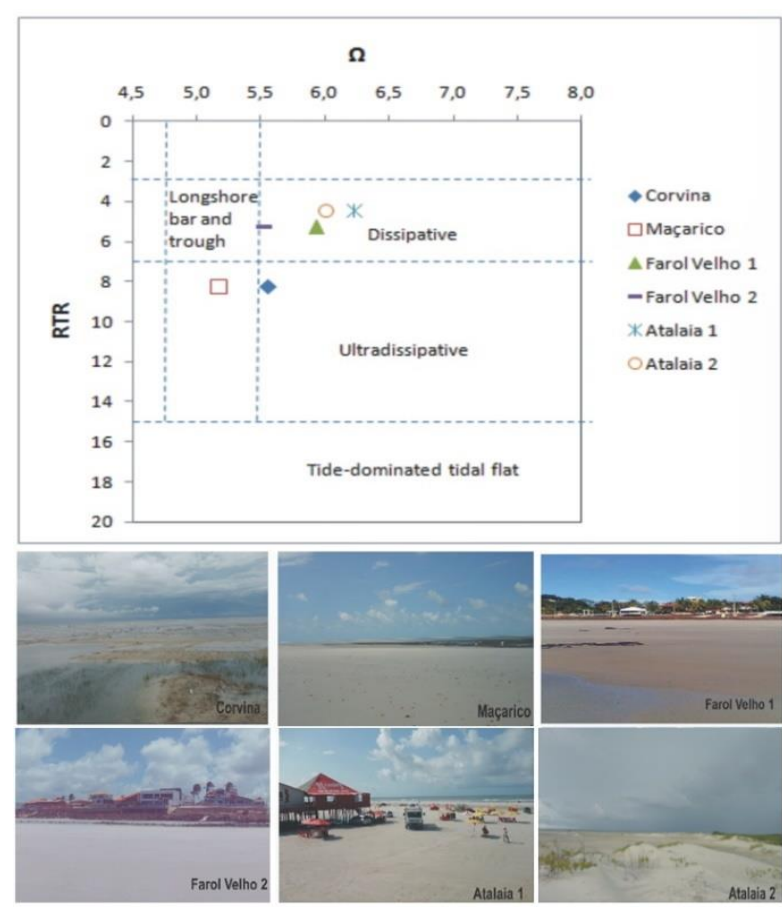

Figura 7. Estados morfodinâmicos identificados nas praias de Salinópolis durante a estação chuvosa. $\Omega$ : segundo a classificação de Wright e Short (1984). RTR: segundo a classificação de Masselink e Short (1993).

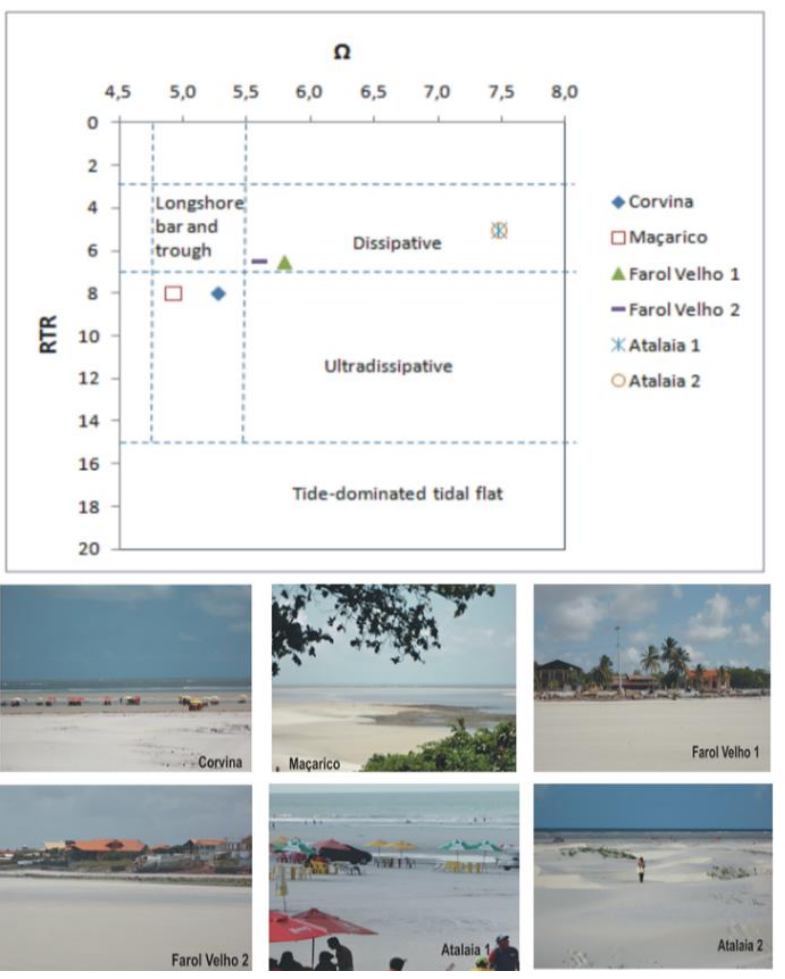

Figura 8. Estados morfodinâmicos identificados nas praias de Salinópolis durante a estação menos chuvosa. $\Omega$ : segundo a classificação de Wright e Short (1984). RTR: segundo a classificação de Masselink e Short (1993).
Contudo, ao longo da costa oceânica de Salinópolis, as praias apresentam declividade bem suaves, abaixo de $1,5^{\circ}$ (Tabela 1). Os menores declives foram verificados na praia do Maçarico (setor oeste), adjacente a um grande canal de maré (Sampaio), que a modela principalmente pelas suas correntes atuantes, gerando um terraço de baixa inclinação. Já os maiores declives foram verificados na praia do Farol Velho (setor central), cuja ocorrência de afloramentos rochosos desde a linha de costa configuram topografia levemente mais acentuada na face praial.

Além disso, outra feição geomorfológica que influenciou na declividade da face praial foram as dunas, como no Atalaia 2, onde elas estiveram presentes inclusive na zona de intermaré superior durante a estação menos chuvosa. A variabilidade na declividade das praias deve-se, principalmente, aos processos sazonais de formação e erosão de dunas frontais, onde há ocorrências destas.

Vale ressaltar também, que a declividade praial pode sofrer variações durante um ciclo de maré. Segundo Calliari et al. (2003), é comum em praias do tipo meso e macromaré, a ocorrência de um padrão mais refletivo por ocasião da preamar e de outro mais dissipativo na baixa-mar.

Quanto às variações na largura de praia $(\sigma \mathrm{Yb})$, estas foram grandes $(9,6 \mathrm{a} 88,4 \mathrm{~m})$ entre as duas estações do ano, sendo que a praia do Maçarico teve a menor variação em relação às demais praias (Tabela 1). Trata-se da praia que se localiza na região mais abrigada da ação direta das ondas. Do contrário, o setor leste, mais exposto, apresentou a maior variação (Tabela 1).

Eichentopf et al. (2018) associaram condições leves de energia de ondas à acumulação de sedimentos mais contínuas.

Transporte Transversal de Sedimentos Embora a morfologia de praia de macromaré seja caracterizada por alto grau de estabilidade, quantidades substanciais de sedimentos podem ser transportadas ao longo destas praias (Sedrati e Anthony, 2007).

Neste trabalho, durante os experimentos com armadilha de sedimentos na zona de espraiamento (intermaré), obteve-se grande quantidade de sedimentos transportados transversalmente na direção onshore, principalmente no setor leste (Figura 9), devido a maior energia de ondas neste local (Tabela 1).

Os sedimentos transportados foram predominantemente areia fina (2.5 a 3 phi) e muito fina (3.5 a 4 phi) em todos os setores da costa. 
Apesar de verificadas quantidades significativas de silte e argila no setor oeste, principalmente (Figura 9). O que indica uma possível zona de sotamar de correntes, ou seja, maior deposição sedimentar.

Tabela 1. Parâmetros morfométricos, hidrodinâmicos e sedimentares registrados durante as estações chuvosa (abril/2013) e menos chuvosa (outubro/2013).

\begin{tabular}{|c|c|c|c|c|}
\hline \multirow[b]{3}{*}{ Parâmetro } & \multicolumn{4}{|c|}{ SETOR OESTE } \\
\hline & \multicolumn{2}{|c|}{ Corvina } & \multicolumn{2}{|c|}{ Maçarico } \\
\hline & Abril & Outubro & Abril & Outubro \\
\hline $\mathrm{D} 50(\Phi)$ & 2.758 & 2.697 & 2.635 & 2.578 \\
\hline Ws $(\mathrm{cm} / \mathrm{s})$ & 2.7 & 2.8 & 2.9 & 3.0 \\
\hline $\mathrm{Hb}(\mathrm{m})$ & 0.6 & 0.7 & 0.6 & 0.7 \\
\hline $\mathrm{T}(\mathrm{s})$ & 4.2 & 4.4 & 4.2 & 4.4 \\
\hline $\operatorname{MSR}(\mathrm{m})$ & 4.9 & 5.2 & 4.3 & 5.2 \\
\hline $\mathrm{Vv}\left(\mathrm{m}^{3} / \mathrm{m}\right)$ & 751 & 1294 & 862 & 1358 \\
\hline$\beta\left(^{\circ}\right)$ & $0.70^{\circ}$ & $0.90^{\circ}$ & $0.53^{\circ}$ & $0.54^{\circ}$ \\
\hline $\mathrm{Yb}(\mathrm{m})$ & 567 & 474 & 583 & 569 \\
\hline \multirow[t]{3}{*}{$\sigma \mathrm{Yb}(\mathrm{m})$} & \multicolumn{2}{|c|}{65.76} & \multicolumn{2}{|c|}{9.59} \\
\hline & \multicolumn{4}{|c|}{ SETOR CENTRAL } \\
\hline & \multicolumn{2}{|c|}{ Farol Velho 1} & \multicolumn{2}{|c|}{ Farol Velho 2} \\
\hline Parâmetro & Abril & Outubro & Abril & Outubro \\
\hline D50 (Ф) & 2.79 & 2.616 & 2.583 & 2.666 \\
\hline Ws $(\mathrm{cm} / \mathrm{s})$ & 2.7 & 2.9 & 2.9 & 3.0 \\
\hline $\mathrm{Hb}(\mathrm{m})$ & 0.8 & 0.8 & 0.8 & 0.8 \\
\hline $\mathrm{T}(\mathrm{s})$ & 4.7 & 4.8 & 4.7 & 4.8 \\
\hline $\operatorname{MSR}(\mathrm{m})$ & 3.4 & 5.3 & 4.0 & 5.3 \\
\hline $\mathrm{Vv}\left(\mathrm{m}^{3} / \mathrm{m}\right)$ & 294 & 356 & 121 & 147 \\
\hline$\beta\left(^{\circ}\right)$ & $1^{\circ}$ & $1.30^{\circ}$ & $1^{\circ}$ & $1.40^{\circ}$ \\
\hline $\mathrm{Yb}(\mathrm{m})$ & 244 & 201 & 158 & 125 \\
\hline \multirow[t]{3}{*}{$\sigma \mathrm{Yb}(\mathrm{m})$} & \multicolumn{2}{|c|}{30.41} & \multicolumn{2}{|c|}{23.33} \\
\hline & \multicolumn{4}{|c|}{ SETOR LESTE } \\
\hline & \multicolumn{2}{|c|}{ Atalaia 1} & \multicolumn{2}{|c|}{ Atalaia 2} \\
\hline Parâmetro & Abril & Outubro & Abril & Outubro \\
\hline D50 (Ф) & 2.856 & 2.744 & 2.832 & 2.768 \\
\hline $\mathrm{Ws}(\mathrm{cm} / \mathrm{s})$ & 2.7 & 2.7 & 2.8 & 2.7 \\
\hline $\mathrm{Hb}(\mathrm{m})$ & 0.9 & 1.1 & 0.9 & 1.1 \\
\hline $\mathrm{T}(\mathrm{s})$ & 5.3 & 5.2 & 5.3 & 5.2 \\
\hline $\operatorname{MSR}(\mathrm{m})$ & 4.0 & 5.3 & 4.0 & 5.3 \\
\hline $\mathrm{Vv}\left(\mathrm{m}^{3} / \mathrm{m}\right)$ & 489 & 491 & 1130 & 1353 \\
\hline$\beta\left(^{\circ}\right)$ & $0.95^{\circ}$ & $1.20^{\circ}$ & $0.53^{\circ}$ & $0.60^{\circ}$ \\
\hline $\mathrm{Yb}(\mathrm{m})$ & 249 & 202 & 679 & 554 \\
\hline
\end{tabular}

\begin{tabular}{l|l|l}
\hline$\sigma \mathrm{Yb}(\mathrm{m})$ & 33.23 & 88.39 \\
\hline
\end{tabular}

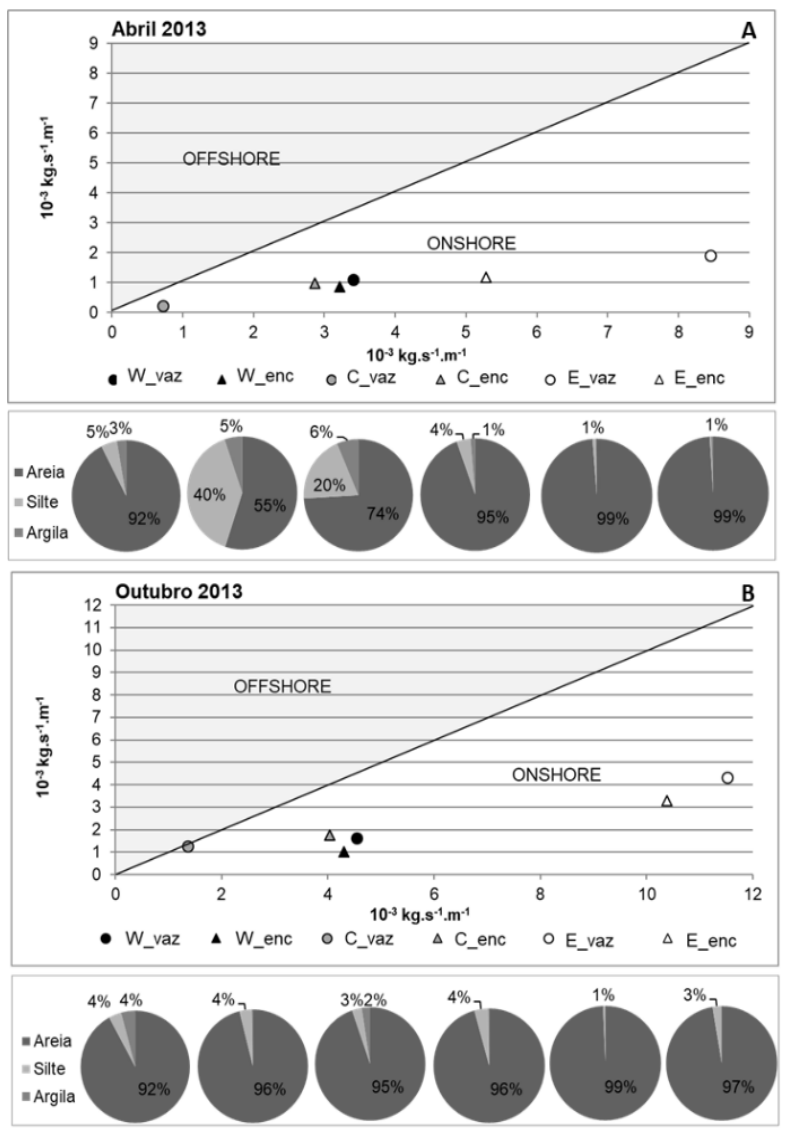

Figura 9. Balanço entre a entrada (onshore) e saída (offshore) de sedimentos pelo espraiamento de ondas nos setores oeste $\mathrm{W}$, central $\mathrm{C}$ e leste $\mathrm{L}$, durante as estações chuvosa (A) e menos chuvosa (B). Vaz: maré vazante. Enc: maré enchente.

Ao analisar os perfis de praia do setor oeste (Figura 10), verificou-se o aumento mais significativo na topografia praial da estação chuvosa a menos chuvosa, ou seja, o maior volume sedimentar durante um período sazonal, dentre os perfis de praia estudados. Este aumento foi de 497 $\mathrm{m}^{2}$ no perfil Maçarico, e $420 \mathrm{~m}^{2}$ no perfil Corvina (Tabela 1).

Já no setor central e no perfil Atalaia 1, onde os perfis de praia obtiveram menor elevação topográfica de uma estação à outra (Figura 10), a quantidade de sedimentos transportados onshore (durante o swash) foi apenas um pouco maior que a quantidade de sedimentos offshore (durante o backwash) (Tabela 2). Ou seja, o balanço sedimentar, apesar de positivo, foi muito baixo, caracterizando pouca estabilidade costeira no setor central.

Notou-se que na porção superior das praias estudadas houve maior acúmulo de sedimentos de 
uma estação climática à outra. Kouekam et al. (2020) também observaram resultados semelhantes principalmente no topo da praia de Idenau (costa oeste de Camarões), mostrando o fenômeno de acreção acompanhado por mudança na elevação.

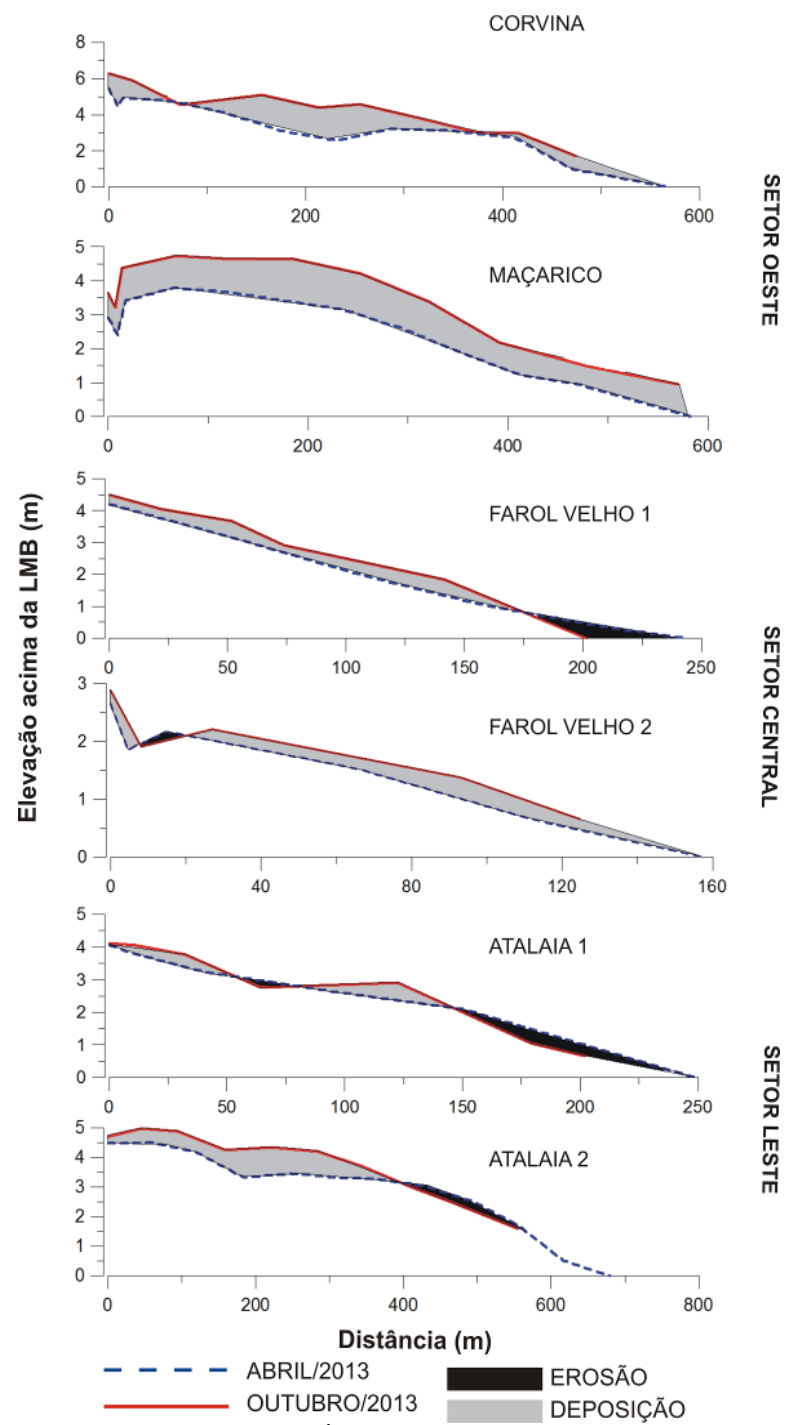

Figura 10. Áreas de erosão e de deposição sedimentar identificadas nas praias entre abril (estação chuvosa) e outubro (estação menos chuvosa) de 2013.

Tabela 2. Taxa de transporte transversal de sedimentos (Qs) verificada nas praias dos setores oeste (W), central (C) e leste (E).

\begin{tabular}{c|c|c|c|c}
\hline \multirow{2}{*}{ SETOR } & \multicolumn{2}{|c|}{ Abril/2013 } & \multicolumn{2}{c}{ Outubro/2013 } \\
\cline { 2 - 5 } & \multicolumn{2}{|c|}{$10^{-3} \mathrm{~kg} / \mathrm{s} / \mathrm{m}$} & \multicolumn{2}{c}{$10^{-3} \mathrm{~kg} / \mathrm{s} / \mathrm{m}$} \\
\cline { 2 - 5 } & ENTRADA & SAÍDA & ENTRADA & SAÍDA \\
\hline W_vaz & 3.4 & 1.1 & 4.6 & 1.6 \\
\hline W_enc & 3.2 & 0.8 & 4.3 & 1.0 \\
\hline C_vaz & 0.7 & 0.2 & 1.4 & 1.3 \\
\hline
\end{tabular}

\begin{tabular}{c|c|c|c|c}
\hline C_enc & 2.9 & 1.0 & 4.0 & 1.7 \\
\hline E_vaz & 8.5 & 1.9 & 11.5 & 4.3 \\
\hline E_enc & 5.3 & 1.2 & 10.4 & 3.3 \\
\hline * Vaz: maré vazante. Enc: maré enchente.
\end{tabular}

Parâmetros Estatísticos Granulométricos McLaren e Bowles (1985) propuseram revelar tendências de transporte sedimentar através de pares de amostras sedimentares associados aos parâmetros estatísticos granulométricos: diâmetro médio, grau de seleção (desvio padrão) e a assimetria das distribuições de frequências granulométricas. Podendo incluir também a curtose, que valida o grau da distribuição granulométrica.

Nas praias de Salinópolis, a média granulométrica dos sedimentos mostrou escala mais frequente entre 2,6 a 2,8 phi, indicando a predominância de areia fina nas praias de Salinópolis (Figuras 11 e 12), com ocorrência de areia média (1 a 2 phi) moderadamente a mal selecionadas, em pontos isolados das praias do Maçarico e Farol Velho 2, próximos aos afloramentos rochosos erodidos pela abrasão das ondas.

O setor leste (Atalaia 1 e 2) foi o que apresentou menor variação granulométrica, sendo especialmente de 2,7 a 3 phi (Figuras 11 e 12), ou seja, com maior ocorrência de sedimentos finos e muito finos, pois neste setor o desenvolvimento de dunas frontais é abundante. Esta menor variação granulométrica é observada pela predominância de sedimentos muito bem selecionadas $(<0,35)$ neste setor (Figuras 11 e 12).

Corroborando com este fato da baixa heterogeneidade dos grãos de sedimentos, o grau de curtose predominante foi de mesocúrtica $(0,90$ a $1,11)$ e leptocúrtica $(1,11$ a 1,5$)$, principalmente para o setor leste, contudo valores de curtose $<0,90$ (platicúrtica) e entre 1,50 a 3,00 (muito leptocúrtica) também ocorreram (Figuras 11 e 12). Estas maiores variações são observadas no setor central, visto que há maior dispersão granulométrica.

A classificação predominante da assimetria foi de positiva $(0,10$ a 0,30$)$ no Atalaia 2 , contudo nos outros perfis de praia estudados predominou a classificação de aproximadamente simétrica $(-0,10$ a 0,10$)$, mas com pequenas variações entre assimetria positiva a negativa ($0,30$ a 0,30$)$ e até mesmo assimetria muito negativa 
(-1 a -0,3), como é o caso do Farol Velho 2 (Figuras 11 e 12).

Perfis que obtiveram aumentos pontuais no diâmetro dos grãos em função da proximidade com afloramentos rochosos (Maçarico, Farol Velho 1 e Farol Velho 2) apresentaram maior ocorrência de assimetria negativa.
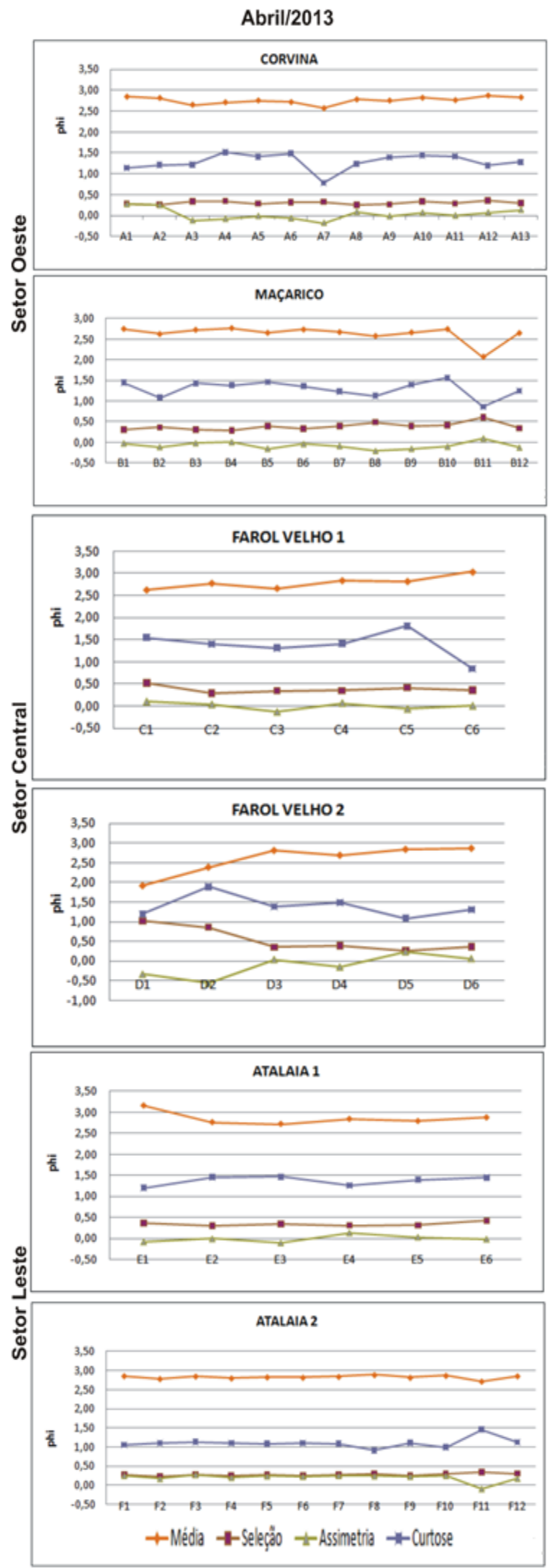

Figura 11. Parâmetros estatísticos granulométricos obtidos para a estação chuvosa. 


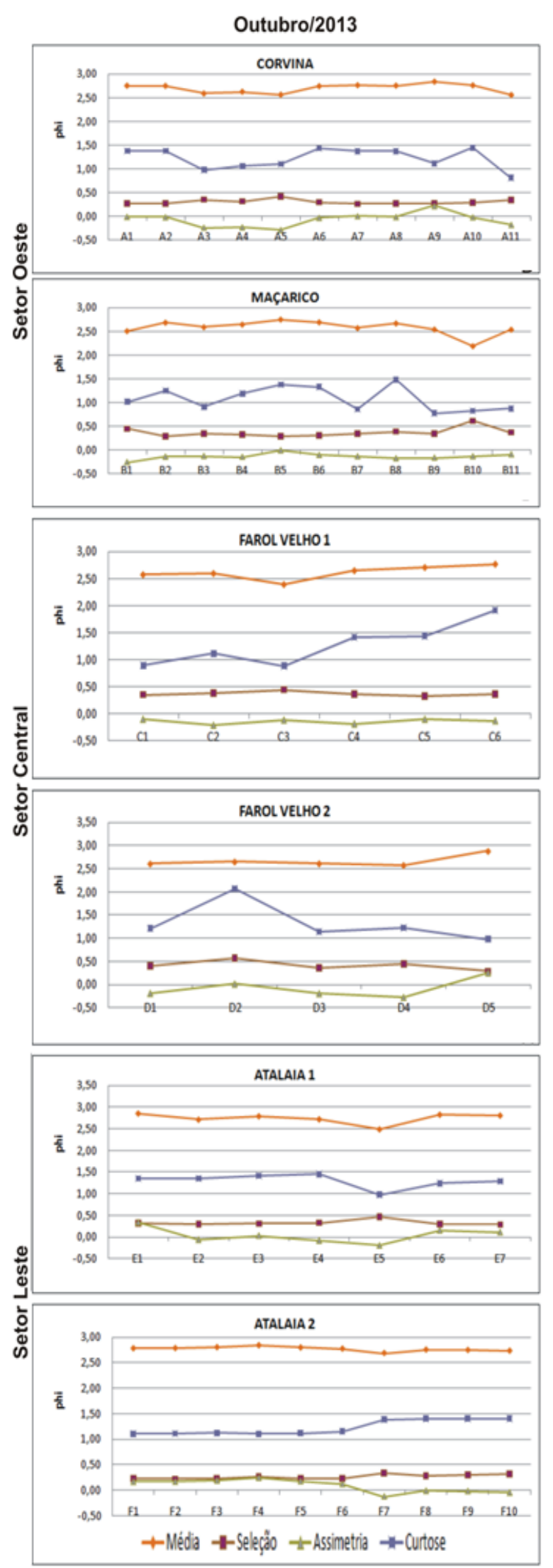

Figura 12. Parâmetros estatísticos granulométricos obtidos para a estação menos chuvosa.
A assimetria aumentou em direção aos extremos da área de estudo (Corvina e Atalaia 2), indicando uma tendência de areia fina e muito fina, bem selecionada e muito bem selecionada, corroborado pela diminuição do grau de seleção nos extremos leste e oeste, e da ocorrência de curtose mesocúrtica e leptocúrtica, ou seja, moderada a baixa variabilidade granulométrica (Figuras 13 e 14).

As áreas de margens de estuários, como as áreas onde situam-se os perfis Corvina e Atalaia 2, estão sujeitas a um grande aporte sedimentar, especialmente de grãos mais finos, devido o melhor retrabalhamento dos sedimentos por efeito conjunto da hidrodinâmica oceânica e estuarina.
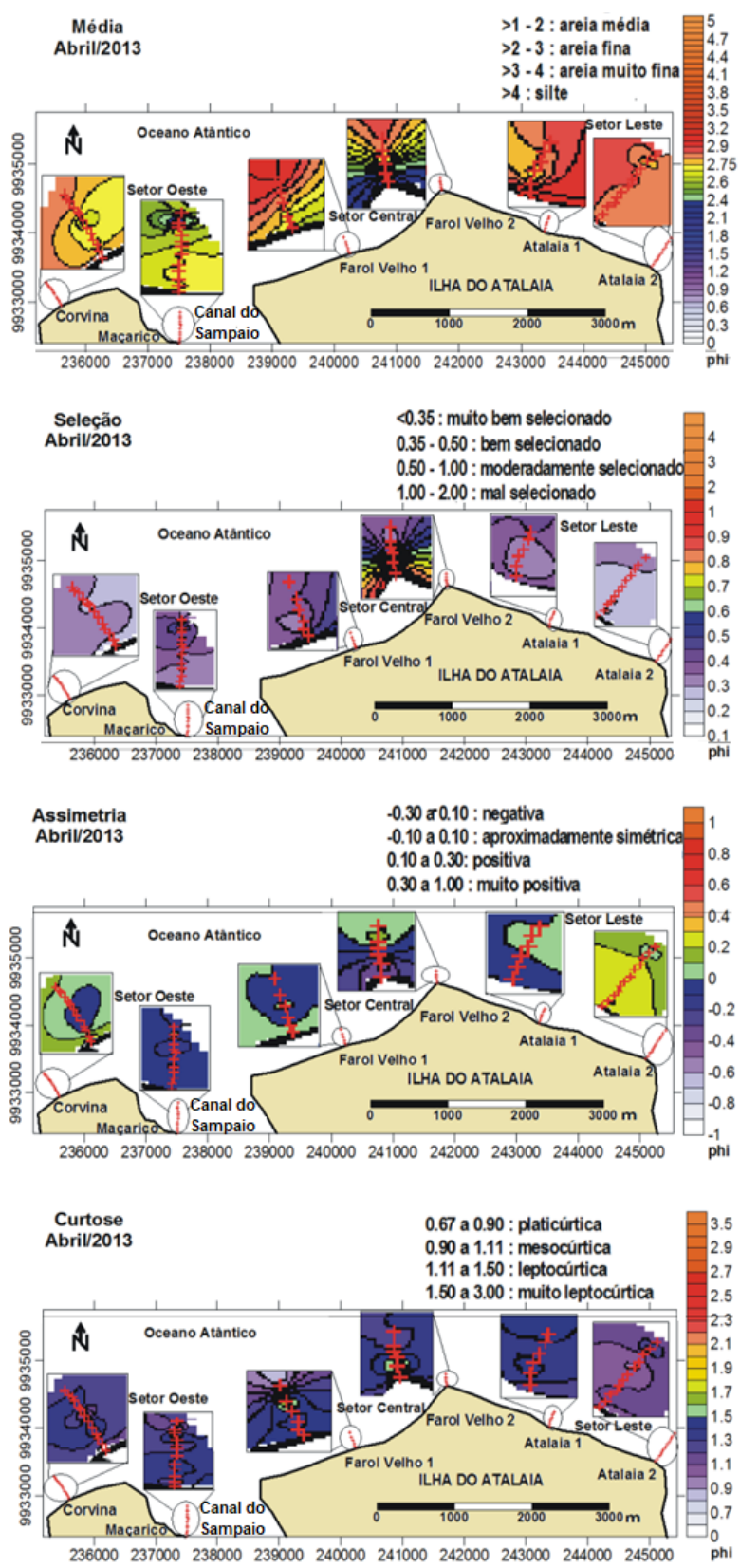

Figura 13. Mapa comparativo da distribuição sedimentar por setor, em abril de 2013 (estação 2098

Ranieri, L. A., El-Robrini, $M$. 
chuvosa), mostrando a tendência granulométrica obtida no emprego dos parâmetros estatísticos.

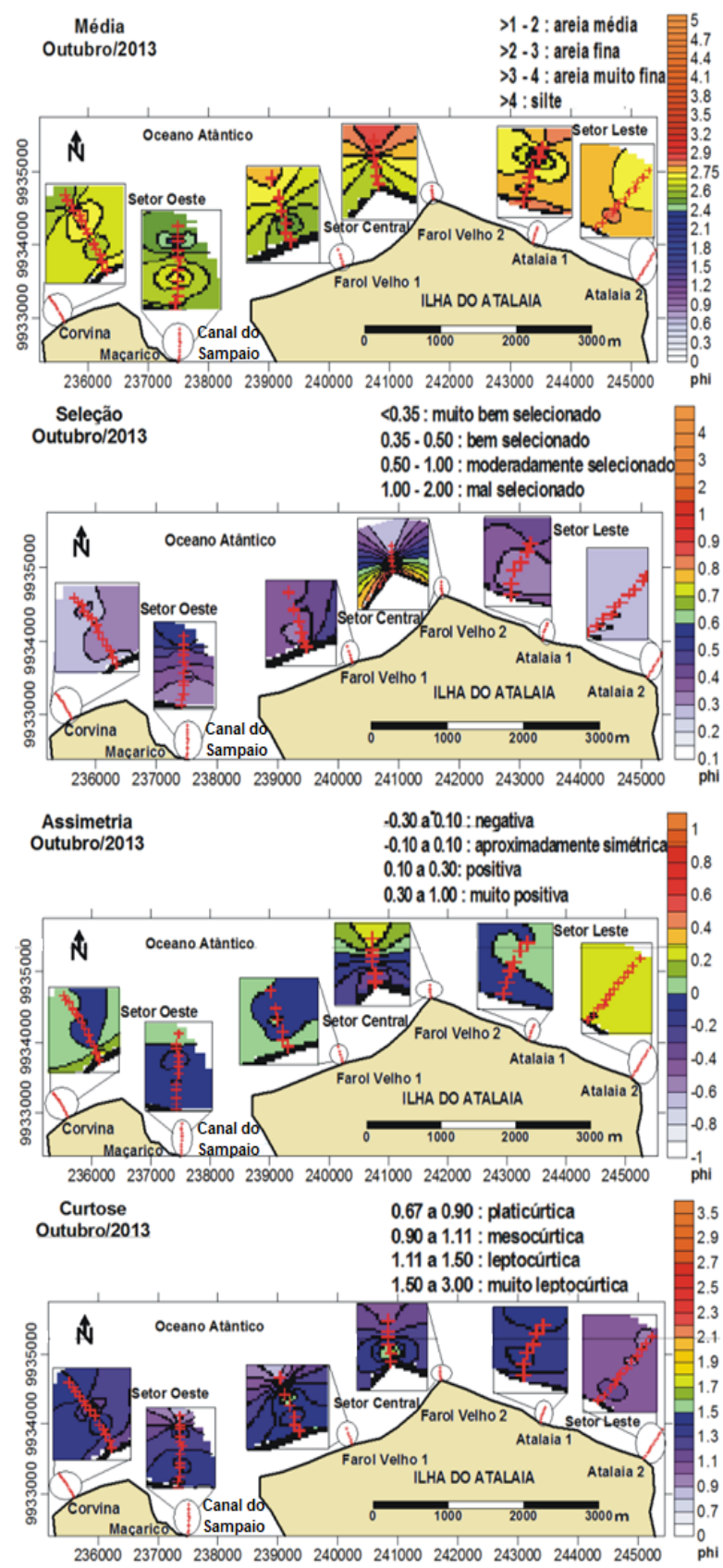

Figura 14. Mapa comparativo da distribuição sedimentar por setor, em outubro de 2013 (estação menos chuvosa), mostrando a tendência granulométrica obtida no emprego dos parâmetros estatísticos.

\section{Conclusão}

Este artigo objetivou mostrar os efeitos da sazonalidade climática sobre a Costa Atlântica amazônica. Esta sazonalidade na região atua como um fator indireto de modulação dos níveis de energia nas praiais oceânicas. Pois seus efeitos sobre a vazão dos sistemas estuarinos e a meteorologia local implicam em maior alcance das águas sobre a linha de costa na estação chuvosa (maior efeito erosivo nas praias) e, ventos mais regulares com redução de tempestades na estação menos chuvosa, formando trens de ondas mais constante, que retrabalham melhor os sedimentos conduzidos da plataforma continental às praias (maior deposição).

As praias de macromarés de Salinópolis exemplificam bem esta alternância nas características morfológicas e sedimentológicas ao longo de um ano. Sendo a variabilidade mediana, que se justifica pela relativa semelhança na composição granulométrica (areias finas e muito finas), na morfodinâmica (praias dissipativas e de banco/calha longitudinais) e na intensidade dos processos físicos costeiros (ventos e ondas de energia baixa a moderada).

A propagação de ondas para o litoral está relacionada às condições climáticas sazonais, à condição diária dos ventos e a influência variável das marés. Quanto a esta última, nota-se que durante as marés altas a altura de ondas foi maior (podendo alcançar valores superiores a $1 \mathrm{~m}$ ), e frequentemente mais baixas durante a baixa-mar.

Em praias, como as do setor oeste de Salinópolis, em que a presença de bancos e calhas longitudinais na zona de intermaré e offshore é constante, as condições resultantes são também de energia de onda moderada, mas com períodos um pouco mais longos durante a baixa-mar, próximo da mesma e no início da enchente. Esta característica topográfica de bancos e calhas longitudinais foi observada nas duas estações climáticas para a praia do Maçarico, a menos exposta ao mar aberto.

A questão da maior e menor exposição às ondas foi determinante para as diferenças na variabilidade dos parâmetros morfométricos nos três setores de Salinópolis. Praias mais expostas apresentaram maiores variações na largura praial, instabilidade morfológica e menor ganho de sedimentos entre as estações do ano. Já as menos expostas apresentaram menores variações na largura praial e maior acreção sedimentar.

Mas, em geral, houve um balanço positivo no volume de sedimentos entre as estações chuvosa e menos chuvosa, como era esperado para a região, devido a sazonalidade das condições climáticas amazônica. Esta transição entre as estações foi acompanhada não somente pelo decréscimo do nível de turbulência devido as menores precipitações, mas também pelo aumento na intensidade dos ventos $\mathrm{e}$, na migração de bancos/barras arenosas. 
As praias de Salinópolis são mais planas durante a estação chuvosa, com baixo número de sistemas de banco-calha longitudinais. Em Corvina e Atalaia 1 estas feições típicas da Morfodinâmica de Praia estiveram presentes.

Durante a estação menos chuvosa ocorreu a migração de barras arenosas submersas em direção à linha de costa, construindo sistemas de banco-calha na zona de intermaré. Esta migração tende a ficar mais limitada quando estes sistemas estão dispostos nesta zona, pois as macromarés semidiurnas induzem um curto período de exposição dos bancos-calhas para os processos hidrodinâmicos.

Calhas longitudinais foram observadas também por depressões topográficas entorno de afloramentos rochosos na praia do Farol Velho e, no setor oeste, em função de ramificações de um pequeno canal de maré que atravessa as praias da Corvina e Maçarico. Estes canais são comuns em praias litorâneas amazônicas.

Sendo assim, os dois estados morfodinâmicos de praia predominantes foram: dissipativo, principalmente na estação chuvosa, e de banco e calha longitudinal, principalmente na estação menos chuvosa.

Durante todo período de monitoramento, ocorreram eventos predominantes de acreção de sedimentos vindos da plataforma continental adjacente. Pois nos três setores da costa, a quantidade de sedimentos transportados na direção onshore às praias (durante o swash) foi maior que a quantidade de sedimentos transportados offshore (durante o backwash), constatado por meio do uso de armadilhas. Contudo, no setor central, o balanço sedimentar (diferença entre a entrada e saída de sedimentos da praia do Farol Velho) foi menor, indicando tendências erosivas a este setor.

Houve predominância de areias finas muito bem selecionadas nas praias oceânicas de Salinópolis, principalmente nos extremos da área de estudo (Corvina e Atalaia 2), pois observa-se o aumento da média granulométrica (phi) e da assimetria e, diminuição do grau de seleção em direção a eles. Por análise da tendência granulométrica, a deposição de sedimentos parece estar bem direcionada a estes extremos, que ainda recebem os sedimentos dos estuários que os margeiam.

No setor central, as condições erosivas são mais favoráveis, visto que há muita exposição de afloramentos rochosos e, que o balanço sedimentar positivo entre a estação chuvosa e menos chuvosa foi baixo neste local.

\section{Agradecimentos}

Aos membros do Grupo de Estudos Marinhos e Costeiros (GEMC) da Universidade Federal do Pará (UFPA) pela parceria na realização deste trabalho. Ao Programa de Pós-Graduação em Geologia e Geoquímica (PPGG) da UFPA e à Fundação do Amparo à Pesquisa do Estado do Pará (FAPESPA) pelo financiamento de bolsa de estudo.

\section{Referências}

Alvarez-Ellacuria, A., Orfila, A., Olabarrieta, M., Medina, R., Vizoso, G., Tintoré, J., 2010. A Nearshore Wave and Current Operational Forecasting System. Journal of Coastal Research 26, 503-509.

ANA. Agência Nacional das Águas, 2013. Sistema de monitoramento hidrológico. Disponível: http://bancodedados.cptec.inpe.br. Acesso: 03 jun. 2013.

Anthony, E.J., Levoy, F., Montfort, O., 2004. Morphodynamics of intertidal bars on a megatidal beach, Merlimont, Northern France. Marine Geology 208, 73-100.

Ayodele, S.O., Madukwe, Y.H., 2019. Granulometric and Sedimentologic Study of Beach Sediments, Lagos, Southwestern Nigeria. International Journal of Geosciences 10, 295-316.

Braga, R.C., Pimentel, M.A.S., Coelho, C., Szlafsztein, C.F., Rollnic, M., 2019. Vulnerabilidade diante da ação energética do mar: Estudo de caso no Município de Salinópolis, Zona Costeira Amazônica, Brasil. Journal of Integrated Coastal Zone Management / Revista de Gestão Costeira Integrada 19, 245 264.

Brand, E., De Sloover, L., De Wulf, A., Montreuil, A., Vos, S., Chen, M., 2019. Cross-Shore Suspended Sediment Transport in Relation to Topographic Changes in the Intertidal Zone of a Macro-Tidal Beach (Mariakerke, Belgium). Journal of Marine Science and Engineering 7, 172.

Brand, E., Montreuil, A.L., Houthuys, R., Chen, M., 2020. Relating Hydrodynamic Forcing and Topographic Response for Tide-Dominated Sandy Beaches. Journal of Marine Science and Engineering, 8, 151. 
Calliari, L.J., Muehe, D., Hoefel, F.G., Toldo Jr, J., 2003. Morfodinâmica praial: uma breve revisão. Revista Brasileira de Oceanografia 51, 63-78.

Cartier, A., Héquette, A., 2015. Vertical distribution of longshore sediment transport on barred macrotidal beaches, northern France. Continental Shelf Research 95, 1-16.

CPTEC. Centro de Previsão de Tempo e Estudos Climáticos, 2013. Instituto Nacional de Pesquisas Espaciais. Modelo WWatch Global. Disponível: http://ondas.cptec.inpe.br/. Acesso: 14 out. 2013.

CPTEC. Centro de Previsão de Tempo e Estudos Climáticos, 2014. Instituto Nacional de Pesquisas Espaciais. Banco de dados meteorológico (Estação Synop). Disponível: http://bancodedados.cptec.inpe.br/downloadB DM/login.do;jsessionid $=$ C6D7F66A4DC3B13 9F487EA7042392AE0.base1. Acesso: 19 jul. 2014.

Darsan, J., 2013. Beach Morphological Dynamics at Cocos Bay (Manzanilla), Trinidad. Atlantic Geology 49, 151-168.

Dean, R.G., 1973. Heuristic model of sand transport in the surf zone. In: Conference of engineering dynamics in the surf zone, Sydney. Proceedings, 208-214.

DHN. Diretoria de Hidrografia e Navegação, 2013. Tábua de marés. Disponível: https://www.marinha.mil.br/chm/tabuas-demare. Acesso: 30 set. 2013.

Eichentopf, S., Caceres, I., Alsina, J. M., 2018. Breaker bar morphodynamics under erosive and accretive wave conditions in large-scale experiments. Coastal Engineering 138, 36-48.

El-Robrini M., Ranieri, L. A., Silva, P. V. M., Alves, M. A. M. S., Gerreiro, J. S., Oliveira, R. R. S., Silva, M. S. F., Amora, P. B. C., ElRobrini M. H. S., Fenzl, N., 2018. Pará, in: Muehe, D. (Ed.), Panorama da Erosão Costeira no Brasil. Ministério do Meio Ambiente, Brasília, pp. 65-166.

Erikson, L., O’Neill, A., Barnard, P., Vitousek, S., Limber, P., 2017. Climate change-driven cliff and beach evolution at decadal to centennial time scales. Coastal Dynamics 2017, 125-136.
Folk, R.L, Ward, W.C., 1957. Brazas river bar: a study in the significance of grain size parameters. Journal of sedimentary petrology 27, 3-26.

Geyer, W.R., Beardsley, R.C., Lentz, S.J., Candela, J., Limeburner, R., Johns, W.E., Castro, B.M., Soares, I.D., 1996. Physical oceanography of the Amazon shelf. Continental Shelf Research $16,575-616$.

Holanda, T.F., Gonçalves, R.M., Lino, A.P., Pereira, P.S., Sousa, P.H.G.O., 2020. Classificação das variações morfodinâmicas e processos costeiros, praia do Paiva, PE, Brasil. Revista Brasileira de Geomorfologia 21, 235251.

Kouekam, A.K., Togue, F.K., Fowe, P.G.K., Ngueguim, J.R., Enow, W.A., Mbang, L.J.E., Ntangyong, I.L., 2020. Impact of hydrodynamic forcings on the morphodynamics of Idenau beach, Western Cameroon coast. Journal of Materials and Environmental Sciences 11, 486498.

Levoy, F., Anthony, E.J., Monfort, O., Larsonneur, C., 2000. Themorphodynamics of megatidal beaches in Normandy, France. Marine Geology 171, 39-59.

McLaren, P., Bowles, D., 1985. The effects of sediment transport on grain-size distributions. Journal of Sedimentary Petrology 55, 457-470.

Masselink, G., Short, A. 1993. The effect of tide range on beach morphodynamics and morphology: a conceptual beach model. Journal of Coastal Research 9, 785-800.

Masselink, G., Anthony, E.J. 2001. Location and height of inter-tidal bars on macrotidal ridge and runnel beaches. Earth Surface Processes and Landforms 26, 759-774.

Nascimento, A.T., Pereira, L.C.C., 2016. Morphodynamic Processes on a Macrotidal Beach in the Eastern Amazon. Journal of Coastal Research SI 75, 427-431.

Oliveira, S.M.O., Pereira, L.C.C., Vila-Concejo, A., 2014. Morphodynamic processes in a macrotidal beach in the Amazon littoral. Quaternary Environment Geosciense 5, 125136. 
Pereira, L.C.C., Vila-Concejo, A., Short, A.D., 2013. Influence of subtidal sand banks on tidal modulation of waves and beach morphology in Amazon macrotidal beaches. Journal of Coastal Research SI 65, 1821-1826.

Pereira, L.C.C., Vila-Concejo, A., Costa, R.M., Short, A.D., 2014. Managing physical and anthropogenic hazards on macrotidal Amazon beaches. Ocean \& Coastal Management 96, 149-162.

Ranieri, L.A, El-Robrini, M., 2012. Comportamento morfodinâmico sazonal da Praia da Romana, Ilha dos Guarás (Nordeste do Pará), como indicativo do transporte litorâneo da área. Pesquisas em Geociências 39, 231-246.

Ranieri, L.A., Robrini, M., 2015. Evolução da linha de costa de Salinópolis, Nordeste do Pará, Brasil. Pesquisas em Geociências, 42, 207-226.

Ranieri, L.A., Robrini, M., 2016. Condição Oceanográfica, Uso e Ocupação da Costa de Salinópolis (Setor Corvina - Atalaia), Nordeste do Pará, Brasil. Journal of Integrated Coastal Zone Management / Revista de Gestão Costeira Integrada 16, 133-146.

Reichmüth, B., Anthony, E.J., 2008. Seasonalscale morphological and dynamic characteristics of multiple intertidal bars. Zeitschrift für Geomorphologie 52, 79-90.

Robin, N.; Levoy, F.; Monfort, O., 2009. Short term morphodynamics of an intertidal bar on megatidal ebb delta. Marine Geology, 260,102120.

Sedrati, M., Anthony, E.J., 2007. Storm-generated morphological change and longshore sand transport in the intertidal zone of a multi-barred macrotidal beach. Marine Geology 244, 209229.

Short, A.D., 1999. Beaches, in: Short, A.D. (Ed.), Handbook of beach and shore face morphodynamics. John Wiley \&. Sons, Chichester, pp.1-19.

Short, A.D., 2003. Australia beach system - The morphodynamic of wave through tidedominated beach-dune systems. Journal of Coastal Research 35, 7-20.
Short, A.D., 2012. Beach Morphodynamics in Australia 1970s-2010. Geographical Research 50, 141-153.

Short, A.D., Hesp, P.A., 1982. Wave beach and dune interactions in southeastern Australia. Marine Geology 48, 259-284.

Sipka, V., Anthony, E.J., 1999. Morphology and hydrodynamics of a macrotidal ridge and runnel beach under modal low conditions. Journal de Recherche Oceanographique 24, 25-31.

Souza Filho, P.W.M., Tozzi, H.A.M., El-Robrini, M., 2003. Geomorphology, land-use and environmental hazards in Ajuruteua macrotidal sand beach, Northern Brazil. Journal of Coastal Research 35, 580-589.

Susanta, P, 2018. Behavioral Pattern of Coastal Morpho-Dynamics of Talasari Coastal Zone, Odisha. International Journal of Scientific Research and Reviews 7, 2140-2152.

Utida, G., Cruz, F.W., Etourneau, J., Bouloubassi, J., Schefuß, E., Vuille, M., Novello, V.F., Prado, L.F., Sifeddine, A., Klein, V., Zular, A, Viana, J.C.C., Turcq, B., 2019. Tropical South Atlantic influence on Northeastern Brazil precipitation and ITCZ displacement during the past 2300 years. Scientific Reports 9, 1-8.

Voulgaris, G., Collins, M.B., 2000. Sediment resuspension on beaches: response to breaking waves. Marine Geology 167, 167-187.

Wentworth, C.K., 1922. A scale of grade and class terms for clastic sediments. Journal of Geology 30, 377-392.

Wright, L.D., Short, A.D., 1984. Morphodynamics variability of surf zones and beaches: a synthesis. Marine Geology 56, 93-118. 